\title{
Integrating fisheries and agricultural programs for food security
}

\author{
Brendan Fisher ${ }^{1,2,3^{*}}$, Robin Naidoo $2,3,4$, John Guernier ${ }^{5}$, Kiersten Johnson ${ }^{6}$, Daniel Mullins ${ }^{5}$, Dorcas Robinson ${ }^{7}$ \\ and Edward H. Allison ${ }^{8}$
}

\begin{abstract}
Background: Despite the connections between terrestrial and marine/freshwater livelihood strategies that we see in coastal regions across the world, the contribution of wild fisheries and fish farming is seldom considered in analyses of the global food system and is consequently underrepresented in major food security and nutrition policy initiatives. Understanding the degree to which farmers also consume fish, and how fishers also grow crops, would help to inform more resilient food security interventions.
\end{abstract}

Results: By compiling a dataset for 123,730 households across 6781 sampling clusters in 12 highly food-insecure countries, we find that between 10 and $45 \%$ of the population relies on fish for a core part of their diet. In four of our sample countries, fish-reliant households are poorer than their counterparts. Five countries show the opposite result, with fish-reliant households having higher household asset wealth. We also find that in all but two countries, fishreliant households depend on land for farming just as much as do households not reliant on fish.

Conclusions: These results highlight the need for food security interventions that combine terrestrial and marine/ freshwater programming if we are going to be successful in building a more resilient food system for the world's most vulnerable people.

Keywords: Food security, Fish, Livelihoods, Wealth, Farming

\section{Background}

With close to a billion people around the world chronically food insecure [1] and more than 100 million children undernourished and underweight [2], food security is a major policy priority across national and international government and non-governmental institutions $[3,4]$. Fish and other aquatic food products provide more than $15 \%$ of animal protein to a third of the planet's population and are important sources of essential micronutrients such as calcium, iron, vitamin $\mathrm{A}$ and zinc [5]. Furthermore, fishing-based activities contribute to the livelihoods of over a half-billion people, with a global trade worth more than $\$ 100$ billion U.S. a year [5]. At the project scale, the contribution of aquatic-source foods to food security is increasingly recognized; however,

\footnotetext{
${ }^{*}$ Correspondence: bfisher@uvm.edu

${ }^{1}$ Rubenstein School of Environment and Natural Resources, University

of Vermont, 81 Carrigan Drive, Burlington, VT 05405, USA

Full list of author information is available at the end of the article
}

this contribution is seldom considered in analyses of the global food system and is consequently underrepresented in major food security and nutrition policy initiatives $[4$, 6-9].

This underrepresentation is in striking contrast to the reality of millions of people's livelihood strategies and diet. Many of the world's poor and food-insecure people employ a diversity of livelihood activities and draw from a diversity of food production systems to meet their daily needs [10-13]. The dynamic where households utilize both terrestrial- and marine/freshwater-based livelihood activities has been documented in coastal areas, and such a portfolio approach to livelihoods is essential for household welfare in many places across the globe [10, 14]. However, programmatic interventions that address food and nutrition security do not typically take a cross-sectoral approach. For example, US Government's global hunger and food security initiative, Feed the Future, led by USAID [4] is an innovative undertaking in 19 countries 
across the developing world, focused on improving nutrition, building capacity and promoting private sector engagement-but initially focused mainly on terrestrial agricultural interventions and value chains (e.g., improving productivity, expanding markets and trade). On the flip side, the World Bank's PROFISH [3] program aims to improve fisheries management with knock-on positive impacts for nutrition and sustainable economic growth. However, it pays little attention to land-based food and nutrition strategies that can, and do, complement fishing livelihoods. So while fish-based and terrestrial-based food security strategies are tightly linked within households and communities in poor parts of the world, major international food security programs often do not adequately address this interconnection in their interventions.

One reason for this on the fisheries side is likely because capture-fishery interventions typically focus on maximizing economic output and are rarely focused on local food security [15]. On the agricultural side, while it has long been argued that a single program focus, like increasing grain yield, may be counterproductive to overall food security if it takes away from a more systemic approach such as an institutional reform [16], rarely are connections with marine livelihoods made, even when agricultural projects are dealing with coastal and river delta or floodplain agriculture [17]. The failure of food security strategies to comprehensively understand varied traditions and livelihood approaches is flawed at best and counterproductive at worst. For example, the failure to integrate traditional ways of subsistence food production and hunting of Northern Canadian Indigenous peoples led to the failure of Canada's "Nutrition North Canada" program. Here, a focus on financial subsidies for food production undermined the broader "wellness" and traditional food production approaches of indigenous peoples [18]. Moving up a level in scale from local cultural approaches, recent analysis of the global food system suggests that even broader connections need to be made, not just between culture, food security and overall health goals, but between food availability, global energy prices and the functioning of financial markets [19], if policies are to help meet food security goals in the longer term.

Such integrated approaches can incur large cost and logistical barriers for large-scale initiatives, but at the project level it is essential to jointly consider the integrated, multiple livelihood strategies, such as with fishing and farming, when planning food security interventions. For example, work in northern coastal Mozambique has revealed that the majority of households $(\sim 70 \%)$ farm and fish in order to secure food and nutrition requirements [20]. Such multiple livelihood strategies change in response to changing socio-ecological conditions.
Drought, storms and diminishing soil quality all force households to modify the amount of time and labor allocated at any one period of time to either fishing or farming (e.g., when drought negatively impacts small-holder farms, more time is allocated to fishing-based activities). Across the developing world livelihood strategies also change in response to changing economic conditions, for example where market access may change the frequency or magnitude of different household activities (e.g., fishing, hunting, farming - [21, 22]).

With the fact that the High Level Panel on Food Security [23], as part of the World Commission on Food Security, concluded that it was critical to make "fish an integral element in inter-sectoral national food security and nutrition policies" (p. 18), and the clear evidence from a suite of sites around the world that mixed-livelihood strategies were not an exception, we aimed to investigate how widespread this mixed-strategy of fishing and farming is across food-insecure regions of the world. To do so, we compiled household survey data for 123,730 households across 6781 sampling clusters in 12 of the 19 Feed the Future countries, representing highly food-insecure regions [data were unavailable for 7 countries] ([24]; see additional file for data sources and references [see Additional file 1]). This is the largest dataset we know of assembled to help us to begin to answer this question. It was assembled to hopefully provide larger-scale empirical evidence to support mixed-livelihood findings from case studies and conservation-development projects. Using these data, we tested to see whether fish-reliant households differed from households not reliant on fish with respect to asset wealth and the amount of land they farm.

If the dynamic of mixed-strategy approaches observed on the project scale is indicative of a general trend, then large-scale programs which target only farming or only fishing will fail to address the breadth of livelihood challenges and opportunities that households face, and will probably fail to deliver a resilient approach to food and nutrition security to those that need it most.

\section{Methods}

To quantitatively examine the prevalence of mixedlivelihood dependencies in countries where large-scale food security interventions are happening, we built a database with wealth and land ownership characteristics for fish-reliant households and their counterparts based on responses from the Demographic and Health Surveys (DHS) for the Feed the Future target countries. These countries were targeted in part because of the high levels of food insecurity. We were able to get nationally representative survey data from DHS for 12 of these target countries-Bangladesh, Cambodia, Ethiopia, Ghana, 
Haiti, Malawi, Mozambique, Nepal, Rwanda, Senegal, Uganda, and Zambia [an additional file documents the survey reference information (see Additional file 1)]. This dataset represented over 6781 sampling "clusters" (often villages or groups of villages) and over 123,730 households (Table 1).

DHS collect nationally and regionally representative survey data where typically between 5000 and 30,000 households per country are surveyed in proportion to the country's population [an additional file shows an example of figure of the coverage of such surveys (see Additional file 2: Figure S1)]. The sampling design is two-stage. First, DHS selects clusters and then households within these clusters. The survey instrument includes modules on household health, education, wealth and diet.

From these surveys, we extracted data related to understanding wealth and land ownership differences between households reliant on fish for protein and households that did not rely on fish for protein. We defined fishreliant households as those households where fish consumption is part of the 24-h dietary recall. The specific DHS question for this was worded as whether or not the household head "Gave child fish or shellfish" the previous day. Wealth and land ownership questions revealed (1) a wealth index based on the presence of a variety of physical assets in a household [25] and (2) the area of agricultural land the household owns or utilizes (a supplementary file details the DHS questions used in this study [see Additional file 1]). We structured the analysis by first (1) characterizing the degree to which fish reliance in households is present across our data set; and then (2) testing whether households that are fish reliant have different levels of wealth and land ownership compared to non-fish-reliant households.

\section{Results}

We found that fish reliance is a major phenomenon across our sample countries. Across 10 of the 12 target countries, between 10 and $45 \%$ of the human population relies on fish for protein (Fig. 1), even though Feed the Future interventions in these countries was initially focused almost exclusively on terrestrial food systems. Such fish reliance represents over 90 million people in these countries alone.

In several countries, fish-reliant households are among the most asset-poor households in these already poor and food-insecure target countries. In four of the 12 countries (Cambodia, Ethiopia, Mozambique and Zambia), fish-dependent households are poorer than their counterparts (Fig. 2a). In Haiti, Malawi, Rwanda, Senegal and Uganda, asset wealth of the average household is significantly higher for households where fish is in the dietary recall than in households where fish is not in the dietary recall (Fig. 2a). In Bangladesh, Ghana and Nepal, there is no statistically significant difference in wealth between the two types of households. Also, in all but two countries (Nepal and Ethiopia, both of which are landlocked nations with limited freshwater fish production capacity and low rates of fish consumption), fish-reliant households use as much agricultural land as households not reliant on fish (Fig. 2b). An additional file contains the results of the statistical tests, for testing the difference in means across households (see Additional file 3: Table S1).
Table 1 Country sample sizes for full dataset; significance tests were performed for households with a valid value for variable for question V414n (see Additional file 3: Table S1)

\begin{tabular}{lllc}
\hline Country & Survey year & Sampling clusters & Households \\
\hline Bangladesh & 2011 & 600 & 8753 \\
Cambodia & 2010 & 611 & 8232 \\
Ethiopia & 2010 & 596 & 11,654 \\
Ghana & 2008 & 408 & 2992 \\
Haiti & 2006 & 339 & 6015 \\
Malawi & 2010 & 849 & 19,967 \\
Mozambique & 2011 & 610 & 11,102 \\
Nepal & 2011 & 289 & 5306 \\
Rwanda & 2010 & 492 & 9002 \\
Senegal & 2011 & 391 & 12,326 \\
Uganda & 2011 & 404 & 7878 \\
Zambia & 2007 & 319 & 6401 \\
\hline
\end{tabular}

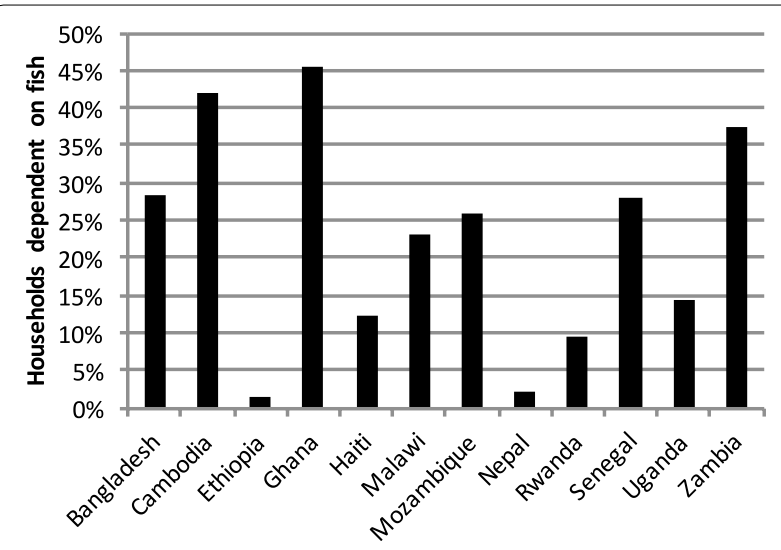

Fig. 1 Percentage of households dependent on fish across 12 of Feed the Future's food-insecure countries. Percentages based on nationally representative household survey data, but are likely to be underestimates given that results are based on dietary recall data for households with children 

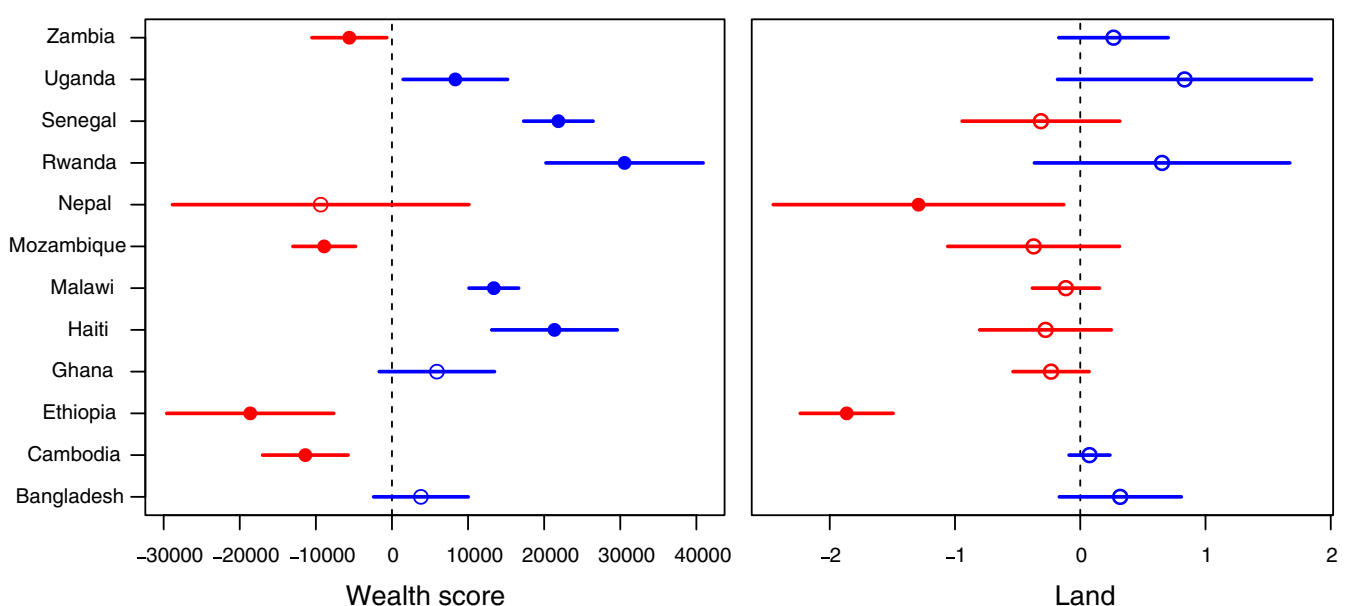

Fig. 2 Wealth and land comparisons between fish-reliant households and non-fish-reliant households for $\mathbf{a}$ wealth, $\mathbf{b}$ access to land. Dashed lines represent no difference between the means for fish-reliant households and households not reliant on fish as measured in their dietary recall. Values in blue are countries where fish-reliant households have more wealth or land than their counterparts (red indicates the converse). Closed circles represent statistically significant differences among household types (open circles no statistical difference from zero), with horizontal lines representing $95 \%$ confidence limits

\section{Discussion}

Our analysis of 123,730 households across 12 highly foodinsecure countries reveals three key points. First, the level of dependence on fish for food across these countries is high. The estimate of roughly 90 million people in these 12 countries who rely on fish is likely to underestimate the level of dependence on fish and fish-based livelihoods. Our metric for fish dependency was based on a question which asked parents whether their children ate any fish in the past $24 \mathrm{~h}$. This is the one consistent question in the survey that allows us to look at fish consumption. We were unable therefore to assess how many households without young children have adults who are reliant on fish for daily nutrition. This unknown number of households would presumably add substantially to our estimate of 90 million fish-dependent individuals. In addition, even in households where we could assess fish reliance, children (especially infants) might be less likely, compared to adults, to receive fish or seafood, particularly when quantities are scarce [26]. It is unclear how our 90 million estimate (for these 12 countries) extrapolated across the globe would compare to other estimates of the reliance on fish protein around the world, but our conservative estimate is that one in five people are fish reliant in these countries. Were this to hold for the globe, our figures are in line with other global estimates [5, 27]. The global figures come from nationally averaged "apparent consumption" (imports and domestic production, minus exports, divided by population size). The global figures are thus averages of indirectly measured averages. The direct figures compiled here, however incomplete, are a useful indicator of reliance on fish protein.
Second, there is no consistent relationship between fish-dependence and wealth across the food-insecure countries in our dataset. In some places, households reliant on fish are wealthier than their counterparts, while the reverse is true in other countries. This is certainly not a novel insight, but simply supports the notion that the relationships between human development and fish/ fishing-based livelihoods are complex $[9,28]$ and a function of many factors, including access to fish, access to alternative sources of income, state of fish stocks, and initial wealth endowment. A full disentanglement of this relationship requires building more sophisticated dataintensive models with information on a suite of potentially important predictor variables that cross a variety of socio-ecological domains. The types of databases necessary for such analyses are beginning to be assembled ([29, 30]; https://www.sesync.org/finding-link-betweenconservation-and-human-health; https://international. ipums.org/international/index.shtml). Due to the lack of a predictive model used in this analysis, our results must be at best considered indicative. Additionally, DHS questionnaires only occasionally include questions that would help to build a more sophisticated understanding of the fishing-farming dynamic within a household (e.g., questions about boat ownership, source of fish protein, household labor allocations). Unfortunately, the data gaps we are trying to fill are systemic with respect to our knowledge of the global scale aspects of fisheries. For example, the estimated number of fishers in the world ranges two orders of magnitude (see [31] for review). Such gaps will need to be filled if we, as a global community, are going to be able to make real progress toward the Sustainable 
Development Goals, and in particular Goal 14-Conserve and sustainably use the oceans, seas and marine resources for sustainable development.

Third, our analysis suggests, across a suite of countries where food security is of paramount importance, that households that typically rely on fish in their diet also rely on farm-based livelihood strategies. In only two landlocked countries with limited surface freshwater resources do our data suggest that fish-reliant households use less land for agriculture than households not reliant on fish. As such, at the household level, livelihoods and food security approaches could be characterized as fishing-farming households, or farming-fishing households [32]. Such a conceptualization is not simply an interesting moniker. The results suggest that existing and forthcoming food security programs should better recognize that the livelihood and coping strategies of foodand nutrition-insecure households and communities are based on both marine/freshwater and terrestrial systems, i.e., fisheries and farms. Of course, geographic conditions and cultural histories predicate that in many parts of the world this farming-fishing duality may not hold. Across the Asian-Pacific and high latitudes in the Arctic, many livelihood strategies rely more solidly on fishing than on terrestrial-based farming. The fact that these systems are increasingly vulnerable to socioeconomic and climate shocks requires a concerted effort to develop strategies that do focus largely on marine resource governance [31, 33]. There are similar parallels in landlocked countries and mountainous regions where livelihoods are predicated upon, and policies will focus on, agricultural and terrestrial resource management.

However, our findings of integrated aquatic-terrestrial food systems dependence in food-insecure countries is likely to apply to a suite of conditions for marginalized people around the world. For example, it might suggest that for coastal, riparian and lakeshore areas across the globe, food security programs and interventions should focus on integrated coastal or wetland food systems that simultaneously address the management and sustainability of fisheries and farms. Evidence is growing that marine protected areas and co-management reserves are improving fish size, abundance and catch [34, 35]. On the terrestrial side, access to nutrients, improved seeds and the use of conservation agricultural techniques have shown to increase soil quality and agricultural yields [36, 37]. Recognizing that fisheries and farms together often support the livelihoods of food-insecure households, communities and nations suggests that linking these activities is warranted. The work of the CARE-WWF Partnership on community managed no-take fishing zones simultaneously with conservation agriculture trainings in Mozambique is an example of this type of integration [20], as was the program on Aquatic Agricultural Systems managed by the WorldFish Center [17], and the 'More Meat, Eggs, Milk and Fish for the Poor' program managed by the International Livestock Research Institute [38]. Explicit evaluation of integrated strategies is wanting; however, there is suggestive evidence of its effectiveness with respect to rice-fish systems [39] and with respect to the integrated nature of the Millennium Development Villages [37]. Additionally, a review of systems in Asia and Africa suggests that the tradeoffs between seemingly competing water uses (such as for irrigated agriculture versus maintaining freshwater flows for fisheries) can be minimal when designed with both uses in mind [40].

For areas without direct access to fish resources but where people have diets traditionally rich in fish (e.g., fermented and dried fish products around the Sahel and inland Central and Southern Africa), maintaining access to fish might mean some focus on sustaining traditional, regional fish-based supply chains, rather than favoring investment in fishing value chains supplying wealthier consumers in developed countries [15]. Sustaining traditional systems will also be critical where fluid markets are either nonexistent or where the development of such markets could lead to crowding out benefits to those most in need. For example: one Cree community in Northern Manitoba has a system of sharing the benefits of the commercial and community fish harvests such that almost $50 \%$ of all community members benefit directly [41]. It is unlikely that a market-oriented approach, in such a context, could deliver such an equitable outcome. Interventions that fail to understand not only the varied livelihood strategies but the varied distributional approaches and cultural knowledge (e.g., traditional customary management of Hawaiian fisheries) will likely fail to deliver sustainable outcomes [42].

Mixed-livelihood strategies (including forest, riverine and pasture-based livelihoods not addressed here) are one of the approaches that marginalized households employ to buffer against social and environmental changes they cannot control. These strategies often rely directly on utilizing natural resources, which for coastal populations across the world means a reliance on well-functioning ecosystems for food security on both land and sea. It also makes explicit the functional linkages between the two systems, such as how nutrient management on land affects pollution at sea [43]. Additionally, managing coastal mangroves and wetlands as fish-nurseries gives these ecosystems explicit economic value and therefore may mitigate future agricultural conversion pressures [44]. Understanding the dynamic of how the management and functioning of ecosystems in one domain affects the other is critical for long-term sustainability of both systems. Integrating fish and farm 
programmatic work explicitly highlights the importance of such socio-ecological reliance and resilience. As such, if agricultural productivity falls due to drought, pests and other problems, then healthy fisheries, managed as commons, can buffer against the worst impacts on poor people. Similarly, if coastal fish stocks are decline, then improved agricultural conditions and programs in the same area could buffer against such shocks. This ability of managers and stakeholders to adapt to changing socioecological conditions has been shown to be critical for long-term ecological resilience (e.g., see [45]).

\section{Conclusion}

In many of the most vulnerable parts of the world, the terrestrial and freshwater/marine resource bases that people rely on are highly stressed and likely to be less stable in the future. With $90 \%$ of the world's assessed fisheries fully or over-exploited [27] and up to $25 \%$ of the world's agricultural lands considered highly degraded [46], stresses on marine and terrestrial resources could already be at unsustainable levels. Population growth, coastal migration, climate change and large-scale land acquisitions by wealthier countries are all likely to exacerbate these pressures on critical natural resources and increase the vulnerability of people who are already food insecure.

Using a large and nationally representative dataset across 12 of the world's most food-insecure countries has shown that households utilize mixed-livelihood welfare strategies. Many locally based NGOs and field programs in coastal and riverine areas witness this dynamic throughout their daily programming. However, at larger scales and in multilateral bureaucratic processes that often decide funding allocations and make strategic intervention decisions, this deeper understanding of mixed-livelihood strategies is often lost. Hence, large programs focused on food security typically follow sectoral approaches that treat the land and sea as distinct. Given the predicted changes we are likely to see in coastal regions over the next few decades, a deeper understanding of dynamic nature of coastal livelihoods at higher levels of decision-making will be critical. Food security programs that discount this dynamic are unlikely to be sustainable and will likely fail to build resilient food systems in the face of the myriad of challenges facing the already poor and food insecure.

\section{Additional files}

Additional file 1. Demographic and Health Survey questions and references used in this study.

Additional file 2: Figure S1. Example of the spatial coverage of DHS surveys-Malawi, Mozambique, and Zambia.

Additional file 3: Table S1. $T$ test results for testing the difference between fish-dependent and non-fish-dependent households for A) wealth B) land.
Abbreviation

DHS: Demographic and Health Surveys.

\section{Authors' contributions}

$B F, R N, J G, K J, D M, D R$ and EHA conceived and designed the research; BF RN performed the analysis; $B F, R N, J G, D M, D R$, EHA wrote the manuscript. All authors read and approved the final manuscript.

\section{Author details}

${ }^{1}$ Rubenstein School of Environment and Natural Resources, University of Vermont, 81 Carrigan Drive, Burlington, VT 05405, USA. ${ }^{2}$ World Wildlife Fund, 1250 24th Street NW, Washington, DC 20037, USA. ${ }^{3}$ Gund Institute, University of Vermont, 617 Main Street, Burlington, VT 05405, USA. ${ }^{4}$ Institute for Resources, Environment and Sustainability, University of British Columbia, 2202 Main Mall, Vancouver, BC V6T 1Z4, Canada. ${ }^{5}$ CARE-WWF Alliance, 596 Av. Martires de Mueda, Maputo, Mozambique. ${ }^{6} 4901$ Cherokee St, College Park, MD, USA. ${ }^{7}$ Poverty Environment and Climate Change Network, CARE International, 1899, Suite 500, L Street NW, Washington, DC 20036, USA. ${ }^{8}$ School of Marine and Environmental Affairs, University of Washington, 3707 Brooklyn Ave NE, Seattle 98105, WA, USA.

\section{Acknowledgements}

Thanks to Taylor Ricketts, Cristina Rumbaitis Del Rio, Althea Skinner, our SESYNC working group and The Chicken Coop Project for valuable feedback.

\section{Competing interests}

The authors declare that they have no competing interests.

\section{Funding}

This work was supported in part by the Oceans and Fisheries Initiative at the Rockefeller Foundation; National Socio-Environmental Synthesis Center (SESYNC) under funding received from the National Science Foundation DBI1052875; and the Sall Family Foundation.

Received: 22 June 2016 Accepted: 8 December 2016

Published online: 10 January 2017

References

1. FAO, IFAD, WFP. State of food insecurity in the world: the multiple dimensions of food security. Rome: FAO; 2013.

2. UNICEF. Joint UNICEF-WHO-The World Bank Child Malnutrition Database; 2012.

3. World Bank. Global Program on Fisheries: strategic vision for fisheries and aquaculture. Washington, DC: The World bank Group; 2011.

4. USAID. Feed the future: the US Government's Global Hunger and Food Security Initiative; 2012

5. Allison EH. Aquaculture, fisheries, poverty and food security. Penang: WorldFish Center; 2011.

6. Belton $\mathrm{B}$, Thilsted $\mathrm{SH}$. Fisheries in transition: food and nutrition security implications for the global South. Glob. Food Secur. 2014;3:59-66.

7. Bene C, Barange M, Subasinghe R, Pinstrup-Andersen P, Merino G, Hemre Gl, Williams M. Feeding 9 billion by 2050-putting fish back on the menu. Food Secur. 2015:7:261-74.

8. Hall SJ, Hilborn R, Andrew NL, Allison EH. Innovations in capture fisheries are an imperative for nutrition security in the developing world. Proc Natl Acad Sci USA. 2013;110:8393-8.

9. Kawarazuka N, Bene C. Linking small-scale fisheries and aquaculture to household nutritional security: an overview. Food Secur. 2010;2:343-57.

10. Allison $\mathrm{EH}$, Ellis F. The livelihoods approach and management of smallscale fisheries. Mar Policy. 2001;25:377-88.

11. Cinner JE, Bodin O. Livelihood diversification in tropical coastal communities: a network-based approach to analyzing 'livelihood landscapes. PLos One. 2010;5. doi:10.1371/journal.pone.0011999.

12. Schaafsma M, Morse-Jones S, Posen P. The importance of local forest benefits: economic valuation of non-timber forest products in the Eastern Arc Mountains in Tanzania. Glob Environ Change. 2014;24:295-305.

13. van Ginkel M, Sayer J, Sinclair F, Aw-Hassan A, Bossio D, Craufurd P, El Mourid M, Haddad N, Hoisington D, Johnson N, et al. An integrated 
agro-ecosystem and livelihood systems approach for the poor and vulnerable in dry areas. Food Secur. 2013;5:751-67.

14. Zamora OB, de Guzman LEP, Saguiguit SLC, Talavera MTM, Gordoncillo NP. Leveraging agriculture to improve nutrition in the Philippines. Food Secur. 2013;5:873-86.

15. Bene C, Lawton R, Allison EH. "Trade matters in the fight against poverty": narratives, perceptions, and (lack of) evidence in the case of fish trade in Africa. World Dev. 2010;38:933-54.

16. Duncan A. The food security challenge for southern Africa. Food Policy. 1998;23:459-75

17. Ratner BD, Cohen P, Barman B, Mam K, Nagoli J, Allison EH. Governance of aquatic agricultural systems: analyzing representation, power, and accountability. Ecol Soc. 2013;18. doi:10.5751/ES-06043-180459.

18. Chin-Yee M, Chin-Yee BH. Nutrition North Canada: failure and facade within the northern strategy. Univ Tor Med J. 2015;92:13-8.

19. Naylor R. Expanding the boundaries of agricultural development. Food Secur. 2011;3:233-51.

20. CARE-WWF. Situation assessment for support to sustainable rural livelihoods in the districts of Angoche, Moma and Pebane. Maputo; 2008.

21. Brashares JS, Arcese P, Sam MK, Coppolillo PB, Sinclair ARE, Balmford A. Bushmeat hunting, wildlife declines, and fish supply in West Africa. Science. 2004:306:1180-3.

22. Schmitt KM, Kramer DB. Road development and market access on Nicaragua's Atlantic coast: implications for household fishing and farming practices. Environ Conserv. 2009;36:289-300

23. HLPE. Sustainable fisheries and aquaculture for food security and nutrition. A report by the High Level Panel of Experts on Food Security and Nutrition of the Committee on World Food Security. Rome; 2014.

24. International I. Demographic and Health Surveys Calverton. Maryland: ICF International; 2004-2012.

25. Rutstein SO, Johnson K. The DHS Wealth Index. DHS Comparative Reports No. 6. Calverton, MD: ORC Macro; 2004

26. Gomna A, Rana K. Inter-household and intra-household patterns of fish and meat consumption in fishing communities in two states in Nigeria. Br J Nutr. 2007;97:145-52.

27. FAO. The state of world fisheries and aquaculture. Rome: Food and Agriculture Organization; 2014.

28. Bene C. When fishery rhymes with poverty: a first step beyond the old paradigm on poverty in small-scale fisheries. World Dev. 2003;31:949-75.

29. Fisher B, Naidoo R. The geography of gender inequality. PLoS One. 2016;11:e0145778.

30. Golden C, Allison EH, Cheung WW, Dey MM, Halpern BS, McCauley DJ, Smith M, Vaitla B, Zeller D, Myers SS. Fall in fish catch threatens human health. Nature. 2016:534:317-20.
31. Kittinger JN. Human dimensions of small-scale and traditional fisheries in the Asia-Pacific Region. Pac Sci. 2013;67:315-25.

32. Geheb K, Binns T.'Fishing farmers' or 'farming fishermen'? The quest for household income and nutritional security on the Kenyan Shores of Lake Victoria. Afr Aff. 1997;96:73-93.

33. Kittinger JN, Koehn JZ, Le Cornu E, Ban NC, Gopnik M, Armsby M, Brooks C, Carr MH, Cinner JE, Cravens A, et al. A practical approach for putting people in ecosystem-based ocean planning. Front Ecol Environ. 2014;12:448-56.

34. Cinner JE, McClanahan TR, MacNeil MA, Graham NAJ, Daw TM, Mukminin A, Feary DA, Rabearisoa AL, Wamukota A, Jiddawi N, et al. Comanagement of coral reef social-ecological systems. Proc Natl Acad Sci USA. 2012;109:5219-22.

35. Kerwath SE, Winker H, Goetz A, Attwood CG. Marine protected area improves yield without disadvantaging fishers. Nat Commun. 2013;4. doi:10.1038/ncomms3347.

36. Nkala P, Mango N, Zikhali P. Conservation agriculture and livelihoods of smallholder farmers in Central Mozambique. J Sustain Agric. 2011;35:757-79.

37. Sanchez P, Palm C, Sachs J, Denning G, Flor R, Harawa R, Jama B, Kiflemariam T, Konecky B, Kozar R, et al. The African millennium villages. Proc Natl Acad Sci USA. 2007:104:16775-80.

38. ILRI. More meat, milk and fish by and for the poor. In Brief No 2011-16. Penang, Malayasia: The WorldFish Center; 2011.

39. Dey MM, Spielman DJ, Haque A, Rahman MS, Valmonte-Santos R. Change and diversity in smallholder rice-fish systems: recent evidence and policy lessons from Bangladesh. Food Policy. 2013;43:108-17.

40. Dugan P, Dey MM, Sugunan WV. Fisheries and water productivity in tropical river basins: enhancing food security and livelihoods by managing water for fish. Agric Water Manag. 2006;80:262-75.

41. Islam D, Berkes F. Indigenous peoples' fisheries and food security: a case from northern Canada. Food Secur. 2016;8:815-26.

42. Friedlander AM, Shackeroff JM, Kittinger JN. Customary marine resource knowledge and use in contemporary Hawai' i. Pac Sci. 2013;67:441-60.

43. Klein CJ, Jupiter SD, Selig ER, Watts ME, Halpern BS, Kamal M, Roelfsema C, Possingham HP. Forest conservation delivers highly variable coral reef conservation outcomes. Ecol Appl. 2012;22:1246-56.

44. Das S, Vincent JR. Mangroves protected villages and reduced death toll during Indian super cyclone. PNAS. 2009;106:7357-60.

45. Aquilera SE, Cole J, Finkbeiner EM, Le Cornu E, Ban NC, Carr MH, Cinner JE, Crowder LB, Gelcich S, Hicks CC, et al. Managing small-scale commercial fisheries for adaptive capacity: insights from dynamic social-ecological drivers of change in Monterey Bay. PLoS One. 2015;10:e0118992.

46. FAO. The State of the World's Land and Water Resources for Food and Agriculture: managing systems at risk. Rome; 2011.

\section{Submit your next manuscript to BioMed Central and we will help you at every step:}

- We accept pre-submission inquiries

- Our selector tool helps you to find the most relevant journal

- We provide round the clock customer support

- Convenient online submission

- Thorough peer review

- Inclusion in PubMed and all major indexing services

- Maximum visibility for your research

Submit your manuscript at www.biomedcentral.com/submit
BioMed Central 